\title{
THE EFFECT OF PUBLIC TARGET ON THE PUBLIC-PRIVATE PARTNERSHIP (PPP) RESIDENTIAL DEVELOPMENT
}

\author{
Yong LIU1, Yelin XU1 , Ziyou WANG ${ }^{2, *}$ \\ ${ }^{1}$ School of Civil Engineering and Architecture, Zhejiang Sci-Tech University, Hangzhou, China \\ ${ }_{2}^{2}$ Department of Building and Real Estate, The Hong Kong Polytechnic University, Hong Kong, China
}

Received 23 January 2018; accepted 4 June 2018

\begin{abstract}
A growing importance of public-private partnership (PPP) in public housing projects has drawn much attention. This paper presents a theoretical analysis exploring the effect of the public target on the private's optimal strategy in a PPP housing project. An option-based model is established to show that an increase in the proportion of public housing will delay the project development. It indicates that the government needs to consider the trade-off between the waiting time and the supply of public housing. On the other hand, due to the delay effect, the expected project value would rise because the private developer is willing to wait for a better environment in the presence of a rise in public housing. Both private and public sector can benefit from this accurate evaluation model and its implications.
\end{abstract}

Keywords: housing supply, optimal development, project risk, public housing, public-private partnership.

\section{Introduction}

Public-private partnerships (PPPs) have been developed into an effective scheme for the provision of large-scale projects which become essential pillar for economic growth (Liu \& Cheah, 2009). PPP, as a means to appeal for fund or to finance the project, has been successfully adopted in the development of asset-based industries, as well as in urban development. Within the PPP framework, public sector who takes the lead in large-scale projects for urban development and redevelopment adopts market-led strategy (Dormois, Pinson, \& Reignier, 2005). Such a strategy inevitably brings about various risks due to its market-driven nature. As most of large-scale projects in the courses of urban development and redevelopment have high risk profiles, both private and public sectors have great interest in balancing risk and return of the project (Leung \& Hui, 2005).

Among various large-scale schemes in urban development, the public housing is the one of most important solutions to the local government and community as it offers a feasible remedy to housing inequality. Public housing plays a prominent part in many countries, either developed or developing ones, during their urban development and sprawl (Aurand, 2013). The local government adhering to the long-term sustainability regards the provision of public housing services to the society as one of its aims. In a majority of cases, the government develops a parcel of empty land to facilitate public housing supply.

Normally, to alleviate its shortfall in financing and techniques, the government would seek appropriate partner to develop the project (Cheah \& Liu, 2006). In general, PPP as an efficient approach is applied to establish collaboration (Xu, Chan, \& Yeung, 2010). In a typical PPP case, the public sector brings the land and offers ancillary funding acting as a promoter (Leung \& Hui, 2005) and a principal driver (Barke \& Clarke, 2015) while the private sector contributes their resources and professional skills (Yuan, Guang, Wang, Li, \& Skibniewski, 2012). As usual, the private developer involved targets at profitability of the project. To attract private partners, the land is sold by the public sector at a discount rate to the private developer (Abdul-Aziz \& Kassim, 2011). In return, the private developer is required to deliver the pre-agreed amount of public housing and the private developer has some freedom to develop the rest of the land for private housing. This is the common collaboration mode in a PPP project which consists of both private and public housing.

The public sector's promotion of such a PPP housing project builds on two main terms: the discount rate (or subsidy proportional to market price) for land acquisition and a target at the supply of public housing. As for

${ }^{*}$ Corresponding author. E-mail: zywang30@gmail.com 
the public target, the local government usually sets up a target of public housing supply to comply with their longterm urban planning. This target can be measured in the proportion of public housing to private housing in a PPP project.

In a PPP project, the private partner has to bear some risks which are transferred from public sector to private. With different levels of involvement and responsibility, PPP allocates risk on an agreed basis between the public and private sectors (Lim, Akintoye, Edwards, \& Hardcastle, 2005). Some of PPP applications have been proved to be inefficient due to various reasons including the underestimation of risks embedded in partnership (Chen \& Doloi, 2008), inappropriate guarantee offered by government (Xu, Yeung, \& Jiang, 2014), and confrontations among different parties (such as resistance from local communities, see Norris \& Hearne, 2016). As such, the risk assessment is imperative to both public and private sectors for the success of PPP projects.

As discussed, PPP complicates the risk issues. On one hand, the private developer is confronted with the uncertainty of investment lag (Bar-Ilan \& Strange, 1996). On the other hand, the private sector has to evaluate the additional risk brought by the public housing. Hence, the private developer has an urgent demand to understand the risks stemming from the public target under market uncertainty, in order to work out optimal strategy prior to project development. Furthermore, the optimal strategy adopted by the private sector including the timing and quantity would affect the outcome of the project, and eventually the achievement of the public target.

Since PPP has been widely introduced to public housing programs (Kwak, Chih, \& Ibbs, 2009; Li et al., 2014), there is a necessity to develop a more accurate valuation considering the impact of the public target for the private sectors. In addition, the implications of this valuation will serve as a reference for the public sector in their monitoring of public housing supply. As few of studies pays attention to the private developer's optimal development strategy in PPP housing projects, this paper intends to investigate the impact of the public target on the private developer's optimal strategy under market uncertainty, and further on the supply of public housing.

In a PPP housing project, the proportion of public housing affects the private developer's decision in several aspects. First, the price of and demand for private housing can be affected by the nearby public housing. Public housing stands a chance of inducing poverty concentration in the neighbourhood (Massey \& Kanaiaupuni, 1993; Jacob, 2004) and even deteriorates the condition of poverty concentration (Hui, Zhong, \& Yu, 2015). Government's longterm urban planning in terms of land use, especially for public housing, is always subject to social polarization of urban societies (Van Kempen, 1994). The residential segregation driven by polarization pushes forward urban poverty.

Second, urban development and redevelopment usually result in large-scale projects of public housing located in the area with relatively poor access to public services and amenities (Talen \& Koschinsky, 2014). For instance, Hui et al. (2015) found that a new project of public housing is more likely to have inferior accessibility to business zone (such as CBD). Many housing studies suggest that the accessibility to CBD or transportation is a determinant factor in land value and house pricing (Heikkila et al., 1989). Thus the private housing prices of PPP project in a relative isolate area may suffer from the shortage of auxiliary facilities.

Third, some evidences are explored to support the price discovery between public and private housing (Ong \& Sing, 2002). The price of private housing is found to be positively correlated with that of public sector. Thus, the proportion of public housing defined by the public target determines the supply of public housing in a public-private project, which influences the pricing of public portion and eventually that of private portion. Besides, the construction costs of public housing proportionately count for the total construction costs. Thus, the proportion of public sector contributes a substantial part to the developer's financial burden.

We develop an option-based model for PPP housing projects subject to the proportion of public housing. By solving the model, we obtain the optimal strategy including the supply of private housing, expected waiting time to develop and option value of project development for the private developer. The theoretical analysis based on the model is conducted to give insights into the effects of the public target on the private developer's optimal decision making in PPP projects.

As previous studies largely concentrate on social and public aspects of decision-making rather than private sector (Leung \& Hui, 2005), our model offers a fundamental analysis of the private developer's developing strategy. The model implications can benefit the public and private sectors in the negotiation of the partnership. In addition, the public sector (local government and related authorities) can take advantage of this study not only to foresee the supplies of public and private housing and relevant timing of provision, but also to balance the development of sub-markets.

Section 1 presents the theoretical model and Section 2 provides the optimal strategies for private developer arising from the model. Section 3 discusses the effect of the public target on such optimal strategies. A numerical analysis is conducted in Section 4 and the conclusion is summarized in the final section.

\section{The scenario and model construction}

This section introduces the real option approach and then presents PPP scenario in private-public housing project and the model construction based on this scenario.

Real option approach is an extension of option pricing framework for financial assets to real (no financial) assets (Titman, 1985). The framework models a series of decision-making at sequential future time points. At each 
point, the decision maker decides whether or not to develop/invest. Since Titman's work, real option-based framework has become a mature approach for the analysis of the feasibility of project investment under market uncertainty. This approach offers a more accurate appraisal method by which the developer can evaluate the relevant benefits and outlays in irreversible investments such as residential development (Quigg, 1993). The merit of the real option approach is it can assess the added value of the flexibility the decision maker can have at each time (Li et al., 2014). Real option approach has been adopted in project valuation for a variety of PPP project including public housing (e.g. Ho, Hui, \& Ibrahim, 2009; Li et al., 2014).

In PPP scenario similar to prevalent models adopted by many countries (see Abdul-Aziz \& Kassim, 2011; Li et al., 2014), the government provides a parcel of land at a discount rate and requests the private developer to construct for the purpose of public housing in return. In this case, the private developer endures the construction cost of public housing. The supply of public housing is in proportion to the supply of private housing in such a PPP project. As a housing project is irreversible and time-consuming, the private developer has to assess the project feasibility through a project valuation prior to development. More specifically, the private developer looks for optimal strategy including the supply of housing, the timing for development and the expected project value (or profit).

The heterogeneity of housing products supplied in this project is defined by the location and project characteristics. It makes this sub-market less perfectly competitive in the area. Hence, the developer is more likely to have monopoly power on the pricing of their private housing products in the area. Let $Q$ denote the supply of private housing. The private house price is derived as a price function of the short-term supply and the long-term market trend (Quigg, 1993). We assume $P=X d(Q)$ where $\mathrm{X}$ is exogenous state variable reflecting the long-term trend and $d(Q)$ measures the short-term supply.

In theory, the first derivative of price with regard to $Q$ should be negative so that $d(Q)^{\prime}<0$. Since the developer is deemed as monopoly supplier in a local market, $d(Q)$ captures the response of price to local housing demand. In this study, the demand function is designed as a linear function shown as:

$$
d(Q)=m-b Q,
$$

where: coefficient $m>0$ is the intercept and $b>0$ captures the sensitivity of price to demand. A greater coefficient $b$ indicates a higher sensitivity of price to demand. The coefficient $b$ is assumed to be constant over developing period. In addition, house price evolves along with the long term trend proxied by the state variable $\boldsymbol{X}$ which follows a geometric Brownian motion shown as:

$$
\frac{d X}{X}=\alpha_{X} d t+\sigma_{X} d w
$$

where: $\alpha_{X}$ is the expected growth rate of $\boldsymbol{X}$ and $\sigma_{X}$ is the standard deviation of growth rate; $d w$ denotes the increment of a standard Wiener process.
Public housing gives rise to poverty concentration (Massey \& Kanaiaupuni, 1993) and even aggravate the neighbourhood poverty (Hui et al., 2015). When private housing is located near public housing, private house prices are negatively affected by public housing mainly due to the effect of poverty concentration (Hui et al., 2015). In addition, private house prices are always positively correlated with public housing (Ong \& Sing, 2002). Hence, an increase in the proportion of public housing further deteriorates private house prices. As the project provides both public and private housing in this scenario, this model takes into account such effect in the project evaluation. That is, the expected private house prices should be negatively adjusted by public housing nearby.

Let $\lambda>0$ denotes the proportion of public housing which is the indicator of the public target). More specifically, $\lambda$ indicates the ratio of public to private housing and thus supply of public housing is $\lambda Q$. Assume the effect of public proportion on private housing prices depends on the ratio $\lambda$ and can be depicted by a function $f(\lambda)$. This function holds several properties: (i) monotonous decreasing as $f^{-}(\lambda)<0$; (ii) $f(0)=1$ when $\lambda=0$, which indicates that the effect is nil if no public housing nearby and then the model reduces to a classical/baseline model; (iii) $0<f(\lambda)<1$, which implies the depreciation effect of public housing on private housing prices. As such, the expected house price at time $t+\delta$ adjusted by $f(\lambda)$ is shown as:

$$
P_{t+\delta}=X_{t+\delta} d(Q) f(\lambda) .
$$

For model simplicity, we assume $f(\lambda)=\exp (-\lambda)$ and equation 3 becomes

$$
P_{t+\delta}=X_{t+\delta} d(Q) \exp (-\lambda) \text {. }
$$

Generally, the supply of housing products $Q$ and ratio of public sector $\lambda$ in such the PPP housing project have to be assigned prior to the development commencement. The intrinsic value of the PPP project at time $t$ could be determined with the supply and the ratio of public housing. Assume the developing period is $\delta$ and thus the new houses can be sold at time $t+\delta$.

The total cost of project development ${ }^{1}, C(Q)$, depends on the supply, can be formulated as $C(Q)=c Q+c_{\lambda} \lambda Q$ where $c$ is the cost of private sector and $c_{\lambda}$ is the cost of public sector with $c_{\lambda} \leq c$. In this case, as the private developer produces the public housing for government for free, the real construction cost becomes $c+c_{\lambda} \lambda$. Associated with the total cost function, the intrinsic value denoted by $\mathbf{v}$ should be the expectation at time $t\left(E_{t}\right)$ of the project profit, expressed as:

$$
\mathrm{v}\left(X_{t}\right)=E_{t}\left[e^{-\rho \delta} P_{t+\delta} Q-C(Q)\right]=e^{-\rho \delta} E_{t}\left[P_{t+\delta}\right] Q-C(Q),
$$

\footnotetext{
1 Usually the total cost contains two parts: the fixed cost and variable cost dependent on the supply amount. In this model the fixed cost is neglected for the model simplicity as it will not affect the outcome and implication of model.
} 
where: $\rho$ denotes the capital cost. Equation (4) shows a typical case in option-based analysis of project evaluation. It indicates that the private developer waits for the optimal timing (denoted by $T$ ) on project development, aiming at the optimal present value of expected earnings. In addition, at the optimal time $(t=\mathrm{T})$ the intrinsic value denoted by $\mathrm{v}\left(X_{T}\right)$ can be shown in the form of

$$
\begin{aligned}
& \mathrm{v}\left(X_{T}\right)=E_{T}\left[e^{-\rho \delta}\left(P_{T+\delta} Q\right)\right] f(\lambda)-C(Q) \\
& =e^{-\rho \delta} E_{T}\left[X_{T+\delta}(m-b Q) Q\right] e^{-\lambda}-\left(c Q+c_{\lambda} \lambda Q\right) \\
& =e^{-\left(\rho-\alpha_{X}\right) \delta} X_{T}(m-b Q) Q e^{-\lambda}-\left(c Q+c_{\lambda} \lambda Q\right) .
\end{aligned}
$$

As such, at any time $t(t<\mathrm{T})$, the value of project (denoted by $\mathbf{V}$ ) is subject to the expected value in accordance with the optimal timing $(\mathrm{T})$ of development. That is

$$
\mathrm{V}\left(X_{t}\right)=\max _{T}\left\{E_{t}\left[\mathrm{v}\left(X_{T}\right)\right] e^{-\rho(T-t)}\right\} .
$$

\section{Optimal project development}

This section gives the analytical solution to the model. The optimal decisions on project development including optimal supply and optimal timing to develop are obtained through the model solution. First, the optimal supply of private housing $\left(Q_{T}\right)$ in this PPP project can be derived from the first-order condition:

$$
\frac{\partial \mathrm{v}\left(X_{T}\right)}{\partial Q}=e^{-\left(\rho-\alpha_{X}\right) \delta} X_{T}(m-2 b Q) e^{-\lambda}-\left(c+c_{\lambda} \lambda\right)=0 .
$$

Thus, the optimal supply $Q_{T}$ can be calculated as:

$$
Q_{T}=\frac{m}{2 b}-\frac{\left(c+c_{\lambda} \lambda\right) e^{\lambda}}{2 b X_{T} e^{-\left(\rho-\alpha_{X}\right) \delta}}=\frac{m}{2 b}-\frac{C e^{\lambda}}{2 b X_{T} e^{-\left(\rho-\alpha_{X}\right) \delta}},
$$

where: $C=c+c_{\lambda} \lambda$ denotes the real unit construction cost. The above formula suggests that if $Q_{T}$ exists, $Q_{T}>0$. This requires that $m$ should be larger than $\frac{\left(c+c_{\lambda} \lambda\right)}{e^{-\left(\rho-\alpha_{X}\right) \delta} e^{-\lambda} X_{T}}$.

Since the coefficient $m$ as the $y$-intercept in inverse demand function indicates the unacceptable housing price which excesses the maximum affordability in the society, this formula gives a lower bound of coefficient $m$.

Based on equation 7, the intrinsic value of project development can be calculated by:

$$
\mathrm{v}\left(X_{T}\right)=\frac{m^{2} X_{T} e^{-\lambda} e^{-\left(\rho-\alpha_{X}\right) \delta}}{4 b}+\frac{C^{2} e^{\lambda} e^{\left(\rho-\alpha_{X}\right) \delta}}{4 b X_{T}}-\frac{m C}{2 b} .
$$

Another concern in project valuation is to determine the optimal timing of development. To fulfil this objective, the partial equilibrium equation is derived to explore the marginal change in project option value. The optimal timing is revealed through solving this equation. Following the framework of real option analysis, the expected increment in the option value should be equal to the expected return which is brought by investing the capital with same amount as the option value into the market. As such, the differential equation is shown as:

$$
E\left[d \mathrm{~V}\left(X_{t}\right)\right]=\rho \mathrm{V} d t .
$$

By applying the Ito's lemma, the instant change in option value is:

$d \mathrm{~V}\left(X_{t}\right)=\left[\alpha_{X} X \mathrm{~V}_{X}+\frac{1}{2}\left(\sigma_{X} X\right)^{2} \mathrm{~V}_{X X}\right] d t+\left[\sigma_{X} X \mathrm{~V}_{X}\right] d w_{X}$

As discussed, the trigger of optimal development is determined by $X_{T}$. When $X<X_{T}$ or $t<T$, the option value of project should satisfy a second order differential equation:

$$
\rho \mathrm{V}=\alpha_{X} X \mathrm{~V}_{X}+\frac{1}{2}\left(\sigma_{X} X\right)^{2} \mathrm{~V}_{X X}
$$

with the initial-condition $\mathrm{V}(0)=0$. Two boundary conditions should be satisfied to solve the differential equation. They are value matching and smooth pasting conditions. First, the continuity of the value function enforces the value-matching condition shown as:

$$
\mathrm{V}\left(X_{T}\right)=\mathrm{v}\left(X_{T}\right) \text {, }
$$

where: $\mathrm{v}\left(X_{T}\right)$ is the intrinsic value of project development given by equation 8 . The other is smooth pasting condition to pin down the free boundary of differential equation defined as:

$$
\mathrm{v}_{X}\left(X_{T}\right)=\mathrm{v}_{X}\left(X_{T}\right) \text {. }
$$

Based on equation 8 , smooth pasting condition is shown as:

$$
\mathrm{V}_{X}\left(X_{T}\right)=\frac{m^{2} e^{-\lambda} e^{-\left(\rho-\alpha_{X}\right) \delta}}{4 b}-\frac{C^{2} e^{\lambda} e^{\left(\rho-\alpha_{X}\right) \delta}}{4 b\left(X_{T}\right)^{2}}
$$

Following the solving process of real option (cf. Dixit \& Pindyck, 1994), the project value at time $t$ subject to two boundary conditions can be shown as:

$$
\mathrm{V}\left(X_{t}, X^{*}\right)=\left\{\begin{array}{ll}
V\left(X_{T}\right)\left(\frac{X_{t}}{X_{T}}\right)^{\kappa}, & X_{t}<X_{T}, \\
V\left(X_{T}\right), & X_{t} \geq X_{T}
\end{array},\right.
$$

where: $\kappa=\frac{1}{2}-\frac{\alpha_{X}}{\sigma_{X}^{2}}+\sqrt{\left(\frac{1}{2}-\frac{\alpha_{X}}{\sigma_{X}^{2}}\right)^{2}+\frac{2 \rho}{\sigma_{X}^{2}}}$. The coefficient $\kappa$ reveals the sensitivity of the project value to the exogenous state variable $X$. In addition, the term $\left(X / X_{T}\right)^{\kappa}$ can be considered as stochastic discount factor in this option pricing framework. The law of one price suggested by the existence of stochastic discount factor promises the uniqueness of option-based value of project development (Wong, 2007).

Based on equations (9-11), the trigger of project development can be calculated as:

$$
X_{T}=\frac{C(\kappa+1) e^{\lambda} e^{\left(\rho-\alpha_{X}\right) \delta}}{(\kappa-1) m} .
$$

The above equation indicates that if trigger $X_{T}$ exists, $X_{T}>0$ which requires that $\kappa>1$ and thus requires the expected return of local housing market should excess the 
expected state growth of state variable, i.e. $\rho>\alpha_{X}$. The relationship between two rates implies a risk premium. In addition, the increase in such risk premium (the disparity between $\rho$ and $\alpha_{X}$ ) leads $\kappa$ to a larger value according to the two inequalities:

$$
\partial \kappa / \partial \rho>0 \text { and } \partial \kappa / \partial \alpha_{X}<0 \text {. }
$$

Substituting $X_{T}$ into equation (7), the optimal supply becomes:

$$
Q_{T}=\frac{m}{b(\kappa+1)},
$$

while substituting $X_{T}$ into equation (8), the optimal intrinsic value of project becomes:

$$
\mathrm{v}_{T}=\frac{m C}{2 b} \frac{\kappa^{2}}{\kappa^{2}-1} .
$$

By solving the model under the uncertainty, the results indicate that the project developer should wait when the exogenous state variable $X_{t}<X_{T}$. Otherwise, the developer should commence the project development with the optimal supply given by equation (13). At the moment, the intrinsic value of project development is determined by equation (14).

Given the initial value of state variable $X_{0}$ at time 0 (suppose $X_{0}<X_{T}$, otherwise the developer should invest immediately), by integrating the probability density function of waiting time until the first arrival of trigger $X_{T}$ (see Sarkar, 2000), the expected waiting time can be derived as:

$$
E\left[t ; X_{0}, X_{T}\right]=\frac{\ln \left(X_{T} / X_{0}\right)}{\alpha_{X}-0.5 \sigma_{X}^{2}} .
$$

Note that the above equation requires the presumption of $\alpha_{X}>0.5 \sigma_{X}^{2}$. In fact, as $X$ follows a geometric Brownian motion, this presumption is guaranteed to have a positive drift in Brownian motion. Equation (15) reveals the positive correlation of the expected waiting time to the trigger value, taking all other parameters $\left(X_{0}, \alpha_{X}, \sigma_{X}\right)$ as constants. It indicates that lower trigger value can shorten the waiting time to develop.

The land policy may compel the private developer to be in face of a penalty, even an adjudication of land losing, if the acquired land has been idle over the stipulated period $^{2}$. In the case that local government sells land to developers, the contract of land leasing restricts the maximum length of waiting time to develop. That is, on the perspective of option pricing, there is a finite expiry period for option of project development. Note that there is no analytical solution to such scenario, but an asymptotic solution of the trigger value can be calculated by using numerical calculation. As the main purpose of this study is to investigate the effects of proportion of public housing on optimal decision for PPP project development, it

\footnotetext{
2 Such policy is implemented in some countries/regions, especially in those markets which are focusing on urbanization. For instance, mainland China and Hong Kong put such policy into practice in their land markets.
}

has trivial impact if the model relaxes the limitation on expiry. As it is convenient if the project development is considered as a perpetual option, the following discussion neglects the finite expiry $N$.

\section{The effect of public supply}

Due to the lack of studies focusing on the effect of public supply on the private developer's optimal decision in project development, this section conducts a series of comparative static analysis to reveal the correlations of proportion of public housing to the optimal timing, optimal private housing supply and project value, taking all other parameters $\left(X_{0}, c, c_{\lambda}, \delta, \rho, \alpha_{X}, \sigma_{X}\right)$ as constant. This analysis could serve as a fundamental guide on optimal development in public-private housing project, on which further studies can build.

Firstly we examine the effects of proportion of public housing (proxied by $\lambda$ ) on the trigger $X_{T}$ and optimal time for project development. These two terms evolve in the tandem as differentiating expected waiting time (equation $15)$ with regard to the ratio of public housing $\lambda$ yields:

$$
\frac{\partial E[t]}{\partial \lambda}=\frac{\partial E[t]}{\partial X_{T}} \frac{\partial X_{T}}{\partial \lambda}=\frac{1}{X_{T}\left(\alpha_{X}-0.5 \sigma_{X}^{2}\right)} \frac{\partial X_{T}}{\partial \lambda},
$$

which shows a positive correlation. As such, the effect of proportion of public housing on these two terms should have the same signs. Then we differentiate the trigger $X_{T}$ (equation 12) with regard to $\lambda$ and yields:

$$
\frac{\partial X_{T}}{\partial \lambda}=\frac{(\kappa+1) e^{\left(\rho-\alpha_{X}\right) \delta}}{(\kappa-1) m}\left(c+c_{\lambda} \lambda+c_{\lambda}\right) e^{\lambda} .
$$

As all the terms are positive, the above equation indicates that $\partial X_{T} / \partial \lambda>0$ and thus $\partial E[t] / \partial \lambda>0$. The ratio of public housing $\lambda$ holds a positive effect on the trigger $X_{T}$ showing that a rise in proportion of public sector leads to a higher trigger of state variable and thus a higher expectation of waiting time to develop. In other words, the private developer would delay the project development in the face of higher proportion of public housing. This leads to remark 1.

Remark 1. The ratio of public housing $\lambda$ has a delay effect on project development in PPP residential project.

The main reason to such delay is that the private developer prefers waiting for a higher trigger value by the delay as a higher trigger value reflects a better external environment and also indicates higher private housing prices (refers to equation 3 ). For this reason, delay would benefit the private developer confronted with a higher proportion of public housing.

Second, we investigate the effect of proportion of public housing on the supply of private housing in PPP project. Take differentiate on equation 13 with respect to ratio of public housing and we have:

$$
\frac{\partial Q_{T}}{\partial \lambda}=0
$$


which shows a trivial correlation between private housing supply and ratio of public housing. In other words, the change in the proportion (or the ratio) of public housing takes no impacts on the private supply. This leads to remark 2.

Remark 2. The proportion of public housing does not affect the private housing supply in a PPP housing project.

The intuition of this remark is as follows. We can use equation 7 to reveal the different channel through which the proportion of public housing affects the private housing supply. Differentiate the supply with regard to the proportion of public housing and have:

$$
\frac{\partial Q_{T}\left(\lambda, X_{T}\right)}{\partial \lambda}=\frac{\partial Q_{T}\left(\lambda, X_{T}\right)}{\partial \lambda}+\frac{\partial Q_{T}\left(\lambda, X_{T}\right)}{\partial X_{T}} \frac{\partial X_{T}}{\partial \lambda},
$$

where: $\frac{\partial Q_{T}\left(\lambda, X_{T}\right)}{\partial \lambda}=-\frac{\left(c+c_{\lambda} \lambda+c_{\lambda}\right) e^{\lambda}}{2 b X_{T} e^{-\left(\rho-\alpha_{X}\right) \delta}}<0$ and

$\frac{\partial Q_{T}\left(\lambda, X_{T}\right)}{\partial X_{T}}=\frac{\left(c+c_{\lambda} \lambda\right) e^{\lambda}}{2 b e^{-\left(\rho-\alpha_{X}\right) \delta}} \frac{1}{X_{T}^{2}}>0$.

The above equation reveals that the total effect can be decomposed into two parts. The first term on the right hand side demonstrates a direct effect of proportion of public housing on the optimal supply which indicates that a higher proportion of public housing could cause a decrease in private housing supply. In other words, it reflects that public housing could crowd out the private housing in local market. On the other hand, the second term on the right hand side demonstrates a complex indirect effect of proportion of public housing through the trigger value (waiting time). This indirect effect consists of two components. The first one shows that $\frac{\partial Q_{T}\left(\lambda, X_{T}\right)}{\partial X_{T}}>0$. A higher trigger value indicates a better state so as to give a rise in the expected housing prices which drives the developer to supply more. Second, as mentioned in remark 1, proportion of public housing has a delay effect on the optimal project development. On the basis of the first aspect, the private developer is more likely to wait in order to take advantage of higher expected housing prices. In total, the indirect effect can alleviate the crowding out effect. In a sum, the direct effect is crowding out effect while the indirect effect is delay effect. As $\partial Q_{T} / \partial \lambda=0$, it implies that these two effects cancel out each other and has a zero-sum effect eventually.

Finally, it is of interest to investigate the effect of proportion of public housing on the intrinsic value of project development in PPP project. Take differentiate on equation 14 with respect to ratio of public housing and have:

$$
\frac{\partial \mathrm{v}_{T}}{\partial \lambda}=\frac{m c_{\lambda}}{2 b} \frac{\kappa^{2}}{\kappa^{2}-1} \text {. }
$$

As $\kappa>1$, the above equation indicates that $\partial \mathrm{v}_{T} / \partial \lambda>0$. Therefore, a higher proportion of public housing induces a higher project value. This leads to remark 3 .

Remark 3. The proportion of public housing $\lambda$ positively affects the intrinsic value of PPP project.
This may be counter-intuitive since usually people think a large scale of public housing near the private property would deteriorate the value of private property (Hui et al., 2015). The intuition is as follows. Similarly, this total effect of $\lambda$ can be decomposed into three parts, i.e. direct and indirect effects. Differentiate the project value defined by equation 5 with regard to the proportion of public housing and yield:

$$
\begin{aligned}
& \frac{\partial \mathrm{v}_{T}\left(\lambda, Q_{T}, X_{T}\right)}{\partial \lambda}=\frac{\partial \mathrm{v}_{T}\left(\lambda, Q_{T}, X_{T}\right)}{\partial \lambda}+ \\
& \frac{\partial \mathrm{v}_{T}\left(\lambda, Q_{T}, X_{T}\right)}{\partial Q_{T}} \frac{\partial Q_{T}}{\partial \lambda}+\frac{\partial \mathrm{v}_{T}\left(\lambda, Q_{T}, X_{T}\right)}{\partial X_{T}} \frac{\partial X_{T}}{\partial \lambda},
\end{aligned},
$$

where:

$$
\begin{aligned}
& \frac{\partial \mathrm{v}_{T}\left(\lambda, Q_{T}, X_{T}\right)}{\partial \lambda}=-e^{-\lambda} e^{-\left(\rho-\alpha_{X}\right) \delta} X_{T}\left(m-b Q_{T}\right) Q_{T}-c_{\lambda} Q_{T}<0, \\
& \frac{\partial \mathbf{v}_{T}\left(\lambda, Q_{T}, X_{T}\right)}{\partial Q_{T}}=e^{-\lambda} e^{-\left(\rho-\alpha_{X}\right) \delta} X_{T}\left(m-2 b Q_{T}\right)-C \text { and } \\
& \frac{\partial \mathrm{v}_{T}\left(\lambda, Q_{T}, X_{T}\right)}{\partial X_{T}}=e^{-\lambda} e^{-\left(\rho-\alpha_{X}\right) \delta}\left(m-b Q_{T}\right) Q_{T}>0 .
\end{aligned}
$$

The first term reflects the direct effect of proportion of public housing. It shows that $\lambda$ has a negative direct effect on the value of project development as an increase in the proportion would reduce the housing price and also give rise to the real construction cost. The second term indicates an indirect effect through the channel of optimal supply of private housing. This term can be ignored with reference to Remark 2. The last term indicates an indirect effect through the trigger value of state variable. Inequality $\frac{\partial \mathrm{v}_{T}\left(\lambda, Q_{T}, X_{T}\right)}{\partial X_{T}}>0$ implies that trigger value positively affects the project value. As multiplied by the delay effect (refers to Remark 1), this indirect effect shows a positive correlation of project value to the proportion. From Remark 3, the total effect is positive implies that the indirect effect brought by the delay effect overwhelms the direct effect. In other words, the private developer is willing to wait longer for a higher trigger value in order to offset the direct negative impacts of public housing on this PPP project.

Note that if the private developer is confronted with a limitation of waiting time, they may not be able to optimally develop the project. A sub-optimal strategy is to wait as long as possible, i.e. to commence the development on the last minute.

\section{Numerical analysis and discussion}

A numerical analysis is conduced to offer a more straightforward illustration than the mathematical expression. By applying equations 12,14 and 15, the value of trigger and the expected waiting time to develop, as well as the optimal project value are calculated and plotted in Figures 1-3 respectively with regard to different proportions of public housing in a range of $[0.10,2]$. Note that, $\lambda$ (lambda) represents the ratio of public to private housing. For instance, 
value of 2 for $\lambda$ indicates the supply of public housing is twice as the supply of private housing.

Table 1 shows the values assigned to the parameters in our analysis. For sensitivity of price to supply, we set 1.10 as many countries have the value larger than 1 (see Caldera \& Johansson, 2013). Parameter $m$ and is randomly selected as it is a constant and matters little in this analysis. The expected market performance including expected market return, expected growth rate and standard deviation of the state variable are set up according to the reasonable values selected from Titman (1985) and Quigg (1993), to mimic a common property market. We set the variable cost for private housing to a unit and proportionally set public housing costs. The ratio is close to the value suggested by Li et al. (2014). The construction period of project and the initial value of state variable are selected randomly in unitisation. For instance, value of 2 for construction period means project development takes 2 units of time periods.

As we employ unitised value for the most of parameters, the values on $y$-axis shown in the following figures themselves are of no meaning. The figures are used to show the patterns of the relationships corresponding to different proportions of public housing.

In general, the trigger value, the expected waiting time and the project value increase with proportion. For the charts of trigger value and optimal waiting time, Figures 1 and 2 display two upward nonlinear curves. These two curves echo with the implications from our theoretical model. An increase in the proportion of public housing leads to a larger trigger value and thus the private developer intends to wait for a better economic environment (indicated by the trigger) to alleviate the expected market uncertainty.

More specifically, Figure 1 displays an obvious convex curve of trigger value while Figure 2 shows a slightly concave curve of expected waiting time, with respect to the public target. Such the concave pattern implies that a unit

Table 1 . The setting of parameters in the numerical analysis

\begin{tabular}{|c|c|l|c|}
\hline Variable & Equation & \multicolumn{1}{|c|}{ Description } & Value \\
\hline$m$ & 1 & $\begin{array}{l}\text { Intercept in the inverse demand } \\
\text { function }\end{array}$ & 3.20 \\
\hline$b$ & 1 & $\begin{array}{l}\text { Slope in the inverse demand } \\
\text { function }\end{array}$ & 1.10 \\
\hline$\alpha_{X}$ & 2 & $\begin{array}{l}\text { Expected growth rate of state } \\
\text { variable }\end{array}$ & 0.06 \\
\hline$\sigma_{X}$ & 2 & $\begin{array}{l}\text { Expected standard deviation of } \\
\text { state variable }\end{array}$ & 0.20 \\
\hline$\rho$ & 4 & $\begin{array}{l}\text { Expected market return rate or } \\
\text { discount rate }\end{array}$ & 0.12 \\
\hline$c$ & 4 & Variable cost for private housing & 1.00 \\
\hline$c_{\lambda}$ & 4 & Variable cost for public housing & 0.85 \\
\hline$\delta$ & 4 & $\begin{array}{l}\text { Development/construction } \\
\text { period for the PPP project }\end{array}$ & 2.00 \\
\hline$X_{0}$ & 15 & Initiation of state variable & 1.50 \\
\hline
\end{tabular}

change $(1 \%)$ in the proportion of public housing when such the proportion is low, brings about more impacts on time delay than that when such the proportion is high. In other words, if the supply plan of public housing is sensitive to time, the local government should not adjust the proportion when the initial proportion is at a low level.

Figure 3 shows a linear relationship between the project value and the proportion of public housing. Although an increase in the proportion of public housing dampens the private house prices and depreciates the whole project, the private developer has to wait for a long time for a better environment to compensate that negative impact.

From the perspective of the private developers, they are keen to know whether it is worth levelling up the proportion of public housing as they understand the increase in proportion of public housing would lead to a higher intrinsic project value. Figure 4 illustrates a nonlinear

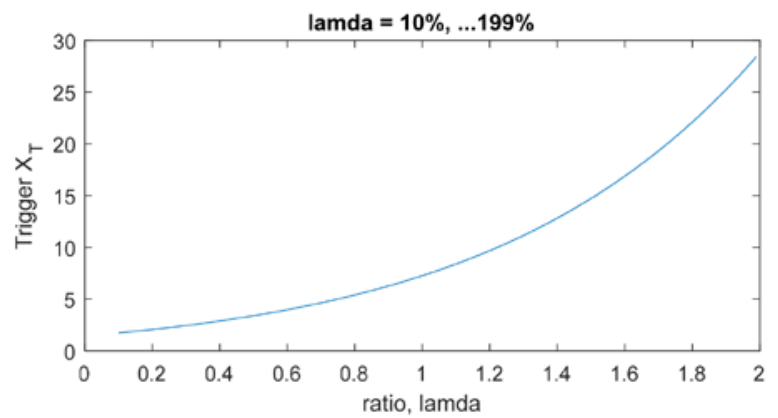

Figure 1 . The plot of the trigger value against the proportion of public housing (lamda)

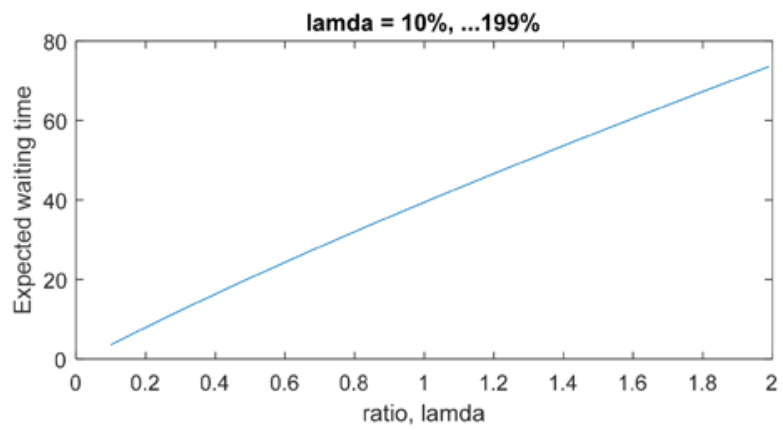

Figure 2. The plot of the expected waiting time against the proportion of public housing (lamda)

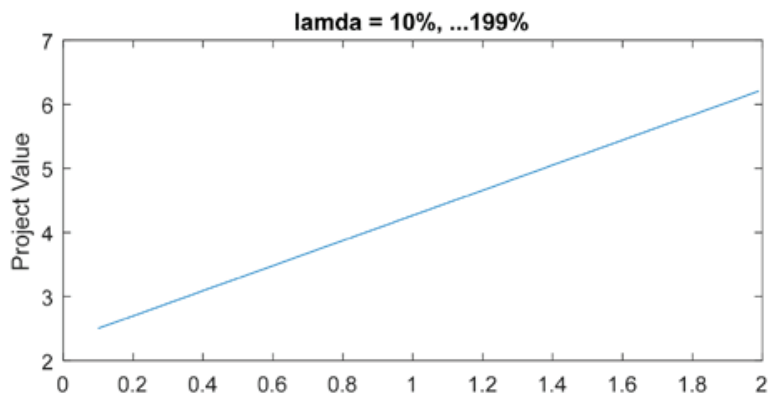

Figure 3. The plot of the project value against the proportion of public housing (lamda) 


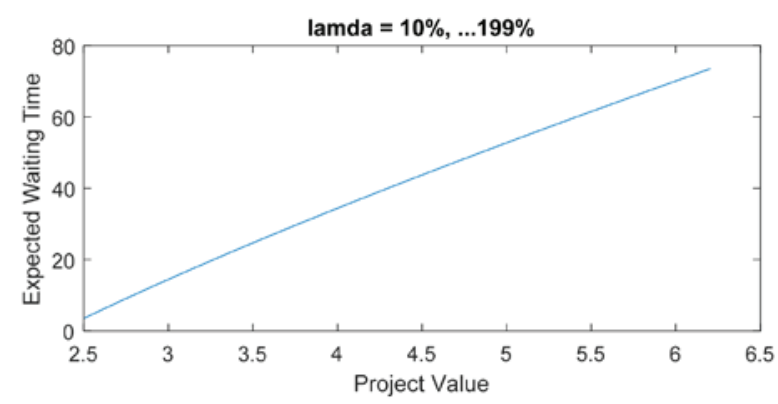

Figure 4. The plot of the expected waiting time against the project value corresponding to the increasing proportion of public housing (lamda from 10\% to 199\%)

relationship between waiting time and project value at each point of proportion from $10 \%$ through $199 \%$. A concave curve indicates that a margin benefit of project value requires less waiting time. In other words, a unit increase in waiting time would bring more margin gain in project value. Theoretically speaking, developers are willing to take higher proportion and to wait longer time if possible.

PPP approach has been widely adopted in many countries (Abdul-Aziz \& Kassim, 2011) and exhibited large potential to improve public housing supply (Li et al., 2014). However, this approach does provide an efficient way but can not be a panacea since the private profit is the most critical factor that hinders the implementation of PPP in a public housing project (Yuan et al., 2012). Our model and findings reveal how the private sector optimises the strategy on the basis of the expected profit. The finding shows that the private sector can benefit from the postponement of the development. This echoes with the value of deferral option verified in Li et al. (2014). For the public sector, the local government on one hand has to fulfil the public target and on the other hand, has to get private sector involved effectively in such PPP projects, in order to have a sustainable development of public housing in the long run (Li, Guo, You, \& Hui, 2016). In addition, the findings demonstrate that for private developer, the waiting leads to a higher project value, which is consistent with the finding of positive premium in Yao and Pretorius (2014). The delays in the supplies of both public and private housing may also stimulate house prices. By contrary, following the spirit of Hui et al. (2015), the delay postpones an insult to injury - the poverty concentration in a developed area may get deferred by not developing public housing at the moment. In light of the above discussion, the public sector should adopt a proper strategy to balance social needs and the progress dominated by private sector, which is the key success factor as suggested in Leung and Hui (2005).

\section{Conclusions}

For sustainable supply of public housing, local government intends to apply public-private partnership (PPP) to alleviate its shortfall in finance and techniques by inviting appropriate private partner to develop the joint project which supplies both private and public housing. To pursue profit from PPP project, the private developer needs to understand project risks under market uncertainty including the risk arising from the public target, in order to make optimal decision prior to project development. As previous studies largely concentrate on social and public aspects rather than private sector decision making (Leung \& Hui, 2005), this paper provides a theoretical analysis to benefit both the public and private sectors by having a profound understanding of how the public target (i.e. the proportion of public housing) affects the private developer's optimal strategy, and further, the supply of public housing.

In this paper, an option-based model is established to capture the private developer's optimal decision making in a PPP housing project. The model implications reveal that the public target (i.e. proportion of public housing) positively affects the waiting time to develop and project value. An increase in the proportion of public housing would induce a delay effect on project development. The private developer is willing to wait longer for a better environment in the face of a rise in public target. In particular, due to the concavity of the expected waiting time, the local government should not increase the proportion when the initial proportion is at a low level, if the government's supply plan is sensitive to time. On the other hand, a change in the proportion of public housing has little impact on the supply of private housing.

The policy implications arising from this model are worth discussing. The private developer has different strategy corresponding to different proportions of public housing in a PPP project. Although a rise in the proportion will not affect private housing supply in the long term, a higher proportion would delay the project development and thus reduce both the public and private supply in the short term. It indicates that the government should consider the trade-off between the waiting time and the supply of public housing. In addition, in many cases, the public sector enforces a limitation to the waiting time in housing project. This makes the PPP project with high proportion of public housing less attractive to the private developer despite of discounted cost of land. If there is no such limitation, the private developer is willing to take a higher proportion as it would lead to a higher project value, though the developer is expected to wait longer.

Notably, the analysis is derived from general case so that the implications are more universal and fundamental. The theoretical model can be extended in accordance with specific PPP schemes, market settings or regulations. That being said, the model requires an adaption when applying to a case of redevelopment or of new zoning. The optionbased model welcomes more intensive study and wider applications in more projects. In the future, the theoretical implications are expected to verify through empirical study by using data in reality. 


\section{Acknowledgements}

We appreciate all the helpful comments from the editors and the anonymous referees. This work was supported by the National Natural Science Foundation of China (NSFC) (Grant No. 71672 180, and in part by Grant No. 71471 166), and the Grant of Zhejiang Provincial Key Research Institute of Philosophy and Social Sciences for Ecological Civilization (Grant No. 17STYB05).

\section{References}

Abdul-Aziz, A. R., \& Kassim, P. J. (2011). Objectives, success and failure factors of housing public-private partnerships in Malaysia. Habitat International, 35(1), 150-157. https://doi.org/10.1016/j.habitatint.2010.06.005

Aurand, A. (2013). Does sprawl induce affordable housing? Growth and Change, 44(4), 631-649. https://doi.org/10.1111/grow.12024

Bar-Ilan, A. \& Strange, W. C. (1996). Investment lags. American Economic Review, 86(3), 610-622.

Barke, M., \& Clarke, J. (2016). Residential growth in Newcastle upon Tyne's city centre: the role of the public and private sectors. Journal of Housing and the Built Environment, 31(1), 141-166. https://doi.org/10.1007/s10901-015-9444-7

Caldera, A., \& Johansson, Å. (2013). The price responsiveness of housing supply in OECD countries. Journal of Housing Economics, 22(3), 231-249. https://doi.org/10.1016/j.jhe.2013.05.002

Cheah, C. Y. J., \& Liu, J. (2006). Valuing governmental support in infrastructure projects as real options using Monte Carlo simulation. Construction Management and Economics, 24, 545-554. https://doi.org/10.1080/01446190500435572

Chen, C., \& Doloi, H. (2008). BOT application in China: driving and impeding factors. International Journal of Project Management, 26(4), 388-398. https://doi.org/10.1016/j.ijproman.2007.07.002

Dixit, A. K., \& Pindyck, R. S. (1994). Investment under uncertainty. Princeton: Princeton University Press.

Dormois, R., Pinson, G., \& Reignier, H. (2005). Path-dependency in public-private partnership in French urban renewal. Journal of Housing and the Built Environment, 20(3), 243-256. https://doi.org/10.1007/s10901-005-9008-3

Heikkila, E., Gordon, P., Kim, J. I., Peiser, R. B., Richardson, H. W., \& Dale-Johnson, D. (1989). What happened to the CBD-distance gradient? Land values in a policentric city. Environment and Planning A, 21(2), 221-232. https://doi.org/10.1068/a210221

Ho, D. K. H., Hui, E. C., \& Ibrahim, M. F. B. (2009). Asset value enhancement of Singapore's public housing Main Upgrading Programme (MUP) policy: a real option analysis approach. Urban Studies, 46(11), 2329-2361. https://doi.org/10.1177/0042098009342451

Hui, E. C. M., Zhong, J., \& Yu, K. (2015). Housing policy, work-residence mismatch and poverty concentration. Habitat International, 48, 198-208. https://doi.org/10.1016/j.habitatint.2015.03.011

Jacob, B. A. (2004). Public housing vouchers and student achievement: evidence from public housing demolitions in Chicago. American Economic Review, 94(1), 233-258.

https://doi.org/10.1257/000282804322970788

Kwak, Y. H., Chih, Y., \& Ibbs, C. W. (2009). Towards a comprehensive understanding of public private partnerships for infrastructure development. California Management Review, 51(2), 51-78. https://doi.org/10.2307/41166480

Leung, B. Y. P., \& Hui, E. C. M. (2005). Evaluation approach on public-private partnership (PPP) urban redevelopments. International Journal of Strategic Property Management, 9, 1-16.
Li, B., Akintoye, A., Edwards, P. J., \& Hardcastle, C. (2005). Critical success factors for PPP/PFI projects in the UK construction industry. Construction Management and Economics, 23(5), 459-471. https://doi.org/10.1080/01446190500041537

Li, D., Chen, H., Hui, E. C. M., Xiao, C., Cui, Q., \& Li, Q. (2014). A real option-based valuation model for privately-owned public rental housing projects in China. Habitat International, 43, 125-132. https://doi.org/10.1016/j.habitatint.2014.03.001

Li, D., Guo, K., You, J., \& Hui, E. C. M. (2016). Assessing investment value of privately-owned public rental housing projects with multiple options. Habitat International, 53, 8-17. https://doi.org/10.1016/j.habitatint.2015.10.018

Liu, J., Cheah, C. Y. J. (2009). Real option application in PPP/PFI project negotiation. Construction Management and Economics, 27(4), 331-342. https://doi.org/10.1080/01446190902807071

Massey, D. S., \& Kanaiaupuni, S. M. (1993). Public housing and the concentration of poverty. Social Science Quarterly, 74(1), 109-122.

Norris, M., \& Hearne, R. (2016). Privatizing public housing redevelopment: grassroots resistance, co-operation and devastation in three Dublin neighbourhoods. Cities, 57, 40-46. https://doi.org/10.1016/j.cities.2015.12.006

Ong, S. E., \& Sing, T. F. (2002). Price discovery between private and public housing markets. Urban Studies, 39(1), 57-67. https://doi.org/10.1080/00420980220099069

Quigg, L. (1993). Empirical testing of real option-pricing models. The Journal of Finance, 48(2), 621-640. https://doi.org/10.1111/j.1540-6261.1993.tb04730.x

Sarkar, S. (2000). On the investment-uncertainty relationship in a real options model. Journal of Economic Dynamics \& Control, 24(2), 219-225.

https://doi.org/10.1016/S0165-1889(99)00005-6

Talen, E., \& Koschinsky, J. (2014). The neighborhood quality of subsidized housing. Journal of the American Planning Association, 80(1), 67-82. https://doi.org/10.1080/01944363.2014.935232

Titman, S. (1985). Urban land prices under uncertainty. American Economic Review, 75(3), 505-514.

Van Kempen, E. T. (1994). The dual city and the poor: social polarization, social segregation and life chances. Urban Studies, 31(7), 995-1015. https://doi.org/10.1080/00420989420080911

Wong, K. P. (2007). The effect of uncertainty on investment timing in a real option model. Journal of Economic Dynamics \& Control, 31, 2152-2167.

https://doi.org/10.1016/j.jedc.2006.07.002

Xu, Y., Chan, A.P., \& Yeung, J. F. (2010). Developing a fuzzy risk allocation model for PPP projects in China. Journal of Construction Engineering and Management, 136(8), 894-903. https://doi.org/10.1061/(ASCE)CO.1943-7862.0000189

$\mathrm{Xu}$, Y., Yeung, J. F., \& Jiang, S. (2014). Determining appropriate government guarantees for concession contract: lessons learned from 10 PPP projects in China. International Journal of Strategic Property Management, 18(4), 356-367. https://doi.org/10.3846/1648715X.2014.971088

Yao, H., \& Pretorius, F. (2014). Demand uncertainty, development timing and leasehold land valuation: empirical testing of real options in residential real estate development. Real Estate Economics, 42(4), 829-868. https://doi.org/10.1111/1540-6229.12052

Yuan, J., Guang, M., Wang, X., Li, Q., \& Skibniewski, M. J. (2012). Quantitative SWOT analysis of public housing delivery by public-private partnerships in China based on the perspective of the public sector. Journal of Management in Engineering, 28(4), 407-420.

https://doi.org/10.1061/(ASCE)ME.1943-5479.0000100 